IOSR Journal of Engineering

May. 2012, Vol. 2(5) pp: 1102-1106

\title{
A Novel Ultra High Fidelity Power Quality and Energy Management Software Using NI LabVIEW
}

\author{
Shishir Sarkar ${ }^{1}$, Dr. S. Chatterji ${ }^{2}$, Shimi S.L ${ }^{3}$, Sonia Rawat ${ }^{4}$ \\ ${ }^{I}$ M.E Student, Electrical Engineering Department, NITTTR, Chandigarh, India \\ ${ }^{2}$ Professor and Head, Electrical Engineering Department, NITTTR, Chandigarh, India \\ ${ }^{3}$ Assistant Professor, Electrical Engineering Department, NITTTR, Chandigarh, India \\ ${ }^{4}$ Director, Advance Scientific Training and Research Organization, Zirakpur, India
}

\begin{abstract}
This paper presents a novel concept of power quality and energy management software using NI LabVIEW. The investigator has developed highly powerful real time power quality and energy management software by using NI LabVIEW, which is capable of doing very complex calculations in fraction of seconds, giving the real time data immediately, hence giving an excellent solution to power quality development. Now a days power quality problems are serious apprehension for electrical power users in view of its negative influence on the electrical equipment and the utility bill. This leads to a greater demand for the power quality measurement tools and especially for the low-cost high fidelity instruments. That is why high fidelity, high precision, high speed real time solutions are required for measuring the power quality parameters. This paper presents an ultimate high fidelity approach based on NI ELVIS Instruments and NI LabVIEW for constant measurement and monitoring of specific power quality parameters.
\end{abstract}

Keywords - NI LabVIEW, Virtual Instruments, Energy auditing software, Power quality measurement, Real time power, voltage, current and energy measurement , Energy management software

\section{INTRODUCTION}

Power quality is a term used to define any occurrence of voltage, current or frequency deviation that results in equipment failure, process interruptions or power system inefficiency. These disturbances are noticeable in the form of harmonics, low power factor, voltage sags/swells, total harmonic distortion, noise, transients etc. The significance of measuring these phenomena comes from the undesired effects caused to the electrical equipment and utility bill.[1] Harmonic disturbances are also responsible for several problems such as erroneous power metering, increase in losses, incorrect operation of protective devices, overheating of different electrical equipment, vibration in motors etc. In high load places, switching on an off of heavy load also creates harmonics and fluctuation in voltage. These should also be monitored and controlled [2] effectively.

\section{NeED AND IMPORTANCE OF POWER QUALITY MONITORING SOFTWARE}

A high power quality is becoming essential now a days for the safety of costly and sophisticated electrical equipments and accessories. It also affects the billing. Therefore there are unlimited benefits of using the power quality software. However some major reasons of using power quality monitoring software are mentioned below:

* The low power quality may lead to damage to the electrical equipments of the facility, often even total failure in its functioning. Thus, it will result in heavy replacement of the parts of the equipment. But this software will help in protecting the equipment by monitoring the power quality in real time.

* It can be used efficiently as energy audit tool [3].

* It continuously monitors and records all events which enable users to analyze trend lines and algorithms to conserve real-time illustrations of performance of different elements and improve reliability, while automatic alerting sends alarms to energy managers before problems occur [4].

* PQ disturbances can range from high frequency impulses caused by lightning strikes, to long-term sustained overvoltages resulting from poor voltage regulation [5]. Therefore the capabilities of the measurement system should also be very high.

* It saves millions of rupees which are invested on power quality measurement devices.

\section{POWER QUALITY AND ENERGY MANAGEMENT SOFTWARE}

The software is divided into two sections. First section is the waveform generation section which is shown in Fig. 1. Second section is the output section which is shown in Fig. 2.

Waveform generation section is the input section. This section is capable of generating sinusoidal, triangular and 
square voltage or current waveforms with or without harmonics/noises. Amplitude, frequency and phase can be controlled [6].

Basically this section is for configuring and testing the output section. Whatever input is given the same output is obtained in the software. This shows its accuracy of measurement.

Output section is the complete analysis and result of input given. It consists of

* Power element

* Voltage and current element

* Energy details.

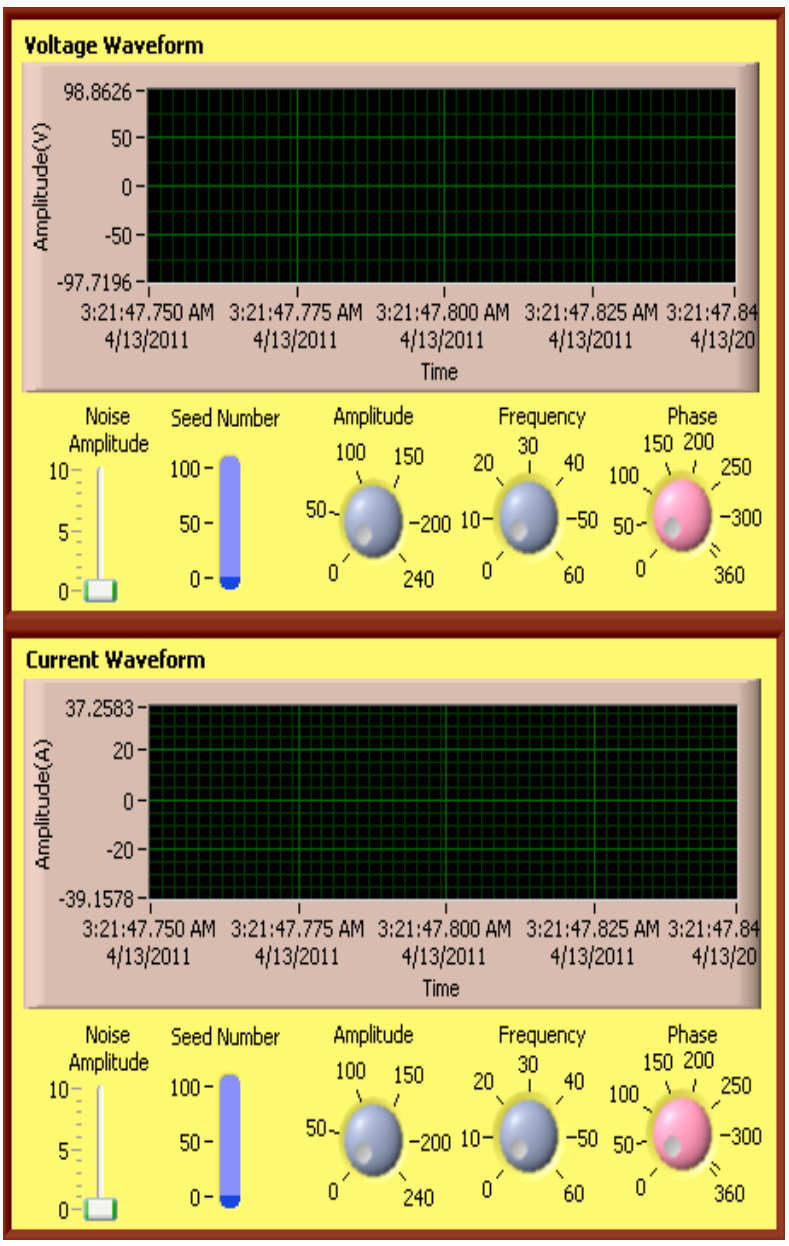

Fig. 1 - Voltage and Current Waveform Generation Section

Power element gives complete real time analysis of different power component like active power, apparent power, reactive power and power factor.

Voltage and current element gives voltage and current frequency, rms voltage and rms current value, voltage and current fundamental vector, fundamental frequency and total harmonic distortion (THD). This section also contains alarms. Following alarms are introduced in this section-
Energy details section gives different energy component like active energy, apparent energy and reactive energy [7, 8].

- Noise alarm.

- High voltage alarm.

- Low voltage alarm.

- High frequency alarm

- Low frequency alarm

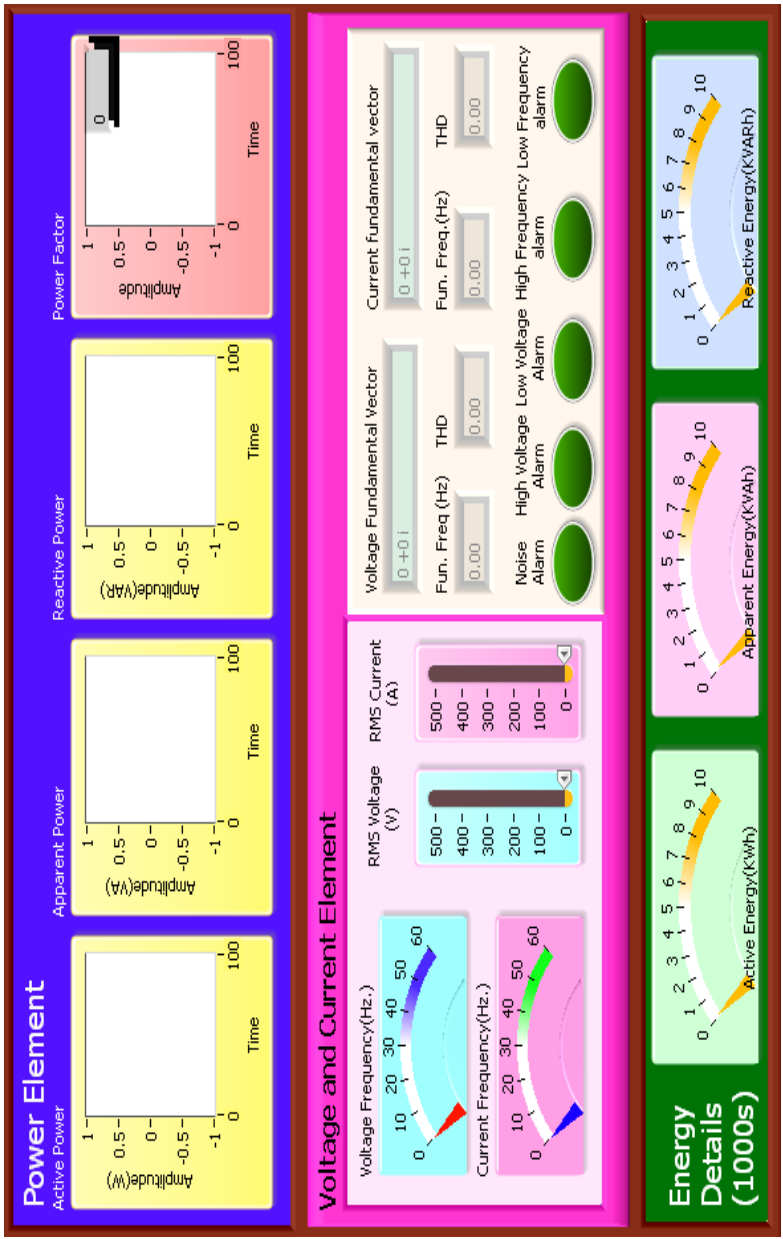

Fig. 2 -Front panel of output section

\section{Case STUdy}

The benefit and utilization of this software is explained in this case study.

\section{Case - 1: Voltage monitoring and alarming}

This software is used for the measurement of voltage component as given in Fig. 3. In Fig. 3, the analysis is shown and the output voltage components are also given. For real time application, investigator has used NI ELVIS and NI DAQ card. Through NI ELVIS real time voltage is given to DAQ card and the DAQ card voltage is given to the software. Then it starts giving real time voltage components and also saves the data it in the computer. If 
IOSR Journal of Engineering

May. 2012, Vol. 2(5) pp: 1102-1106

the frequency or voltage or noise goes beyond the set standard value, then alarm is initiated and green light becomes red.

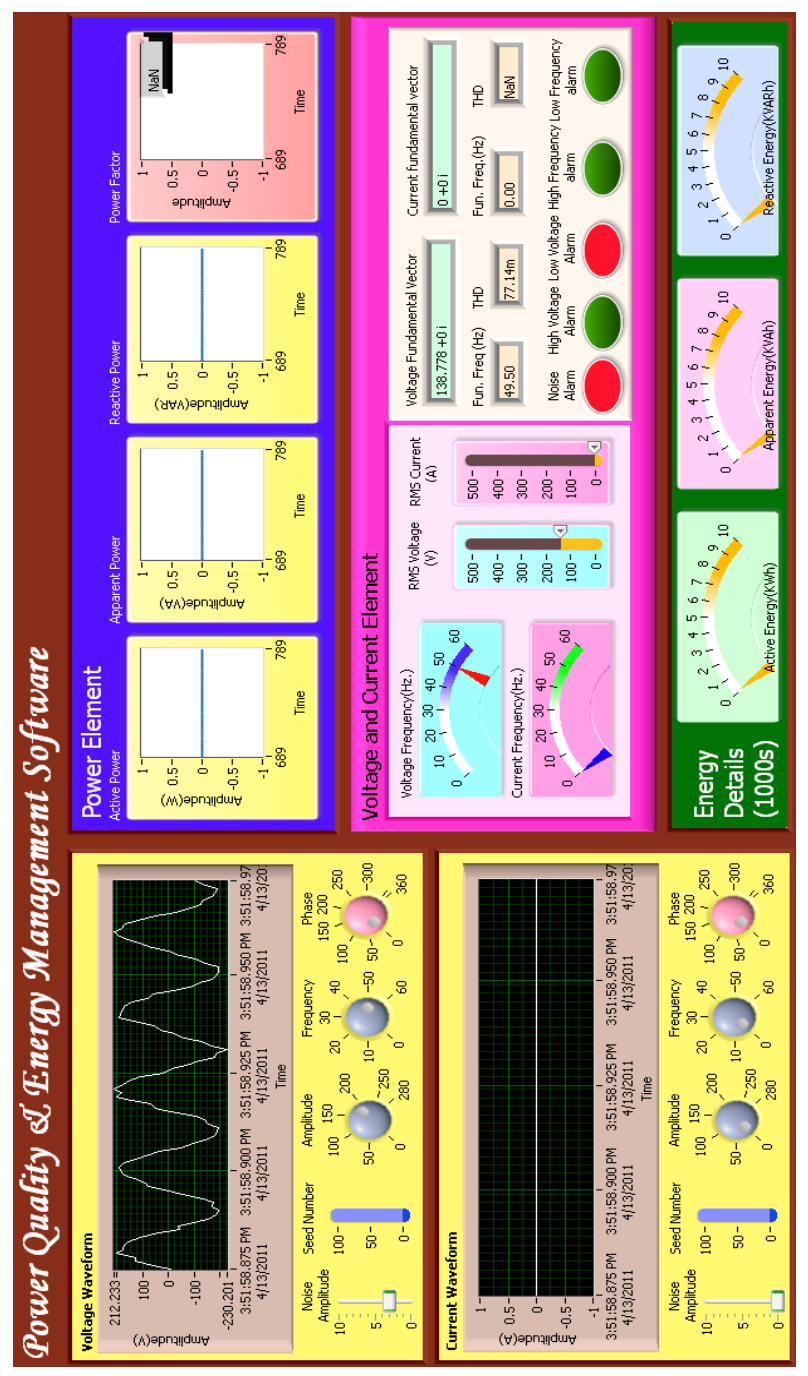

Fig. 3 - Voltage monitoring and alarming

Case - 2: Current monitoring and alarming

This software is also used for the measurement and monitoring of current components as given in Fig. 4. For real time application, the investigator has used NI ELVIS hardware and DAQ Card. In Fig. 4, the analysis is shown and the output voltage components are also given.

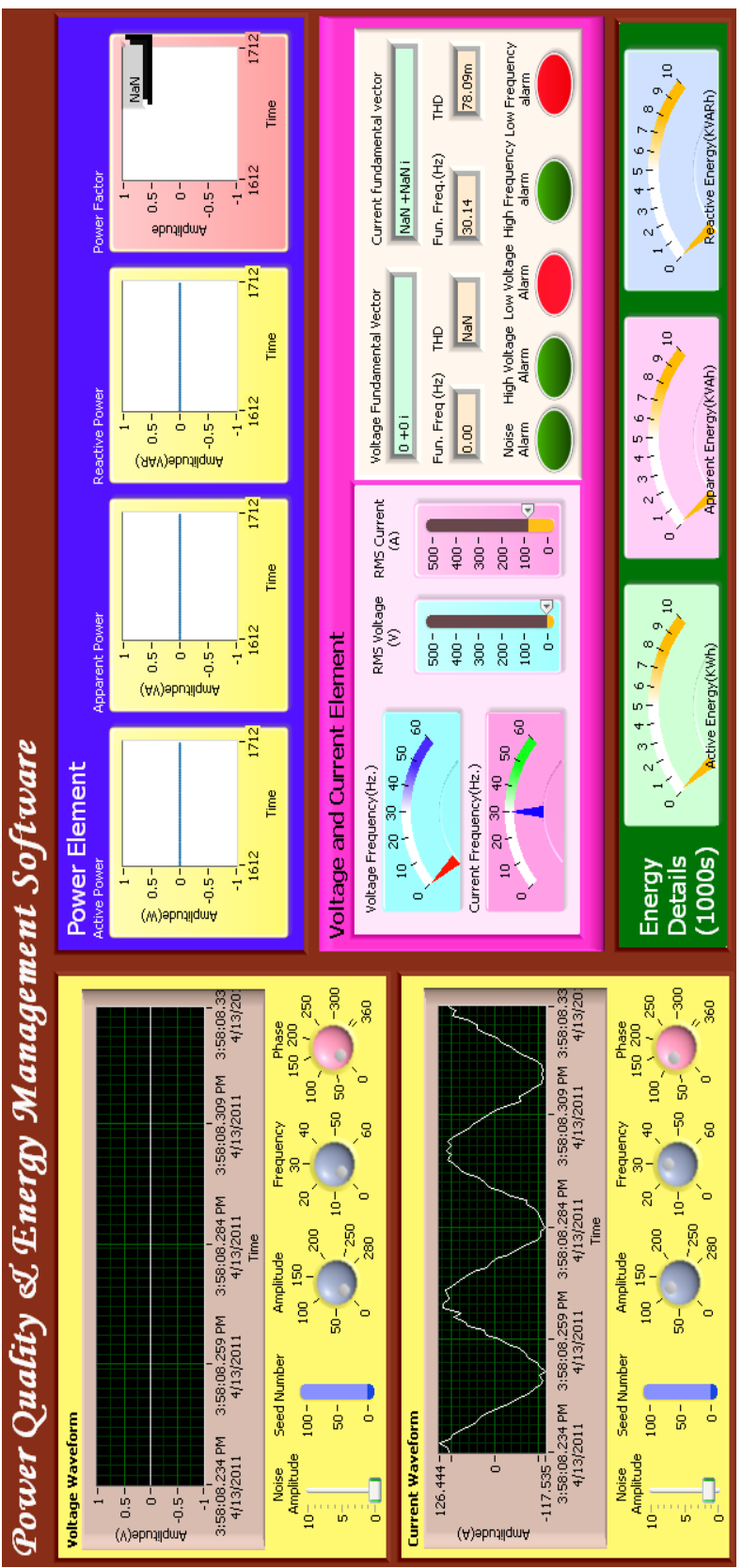

Fig. 4 - Current measurement and monitoring

Case - 3: Power component and power factor measurement

This software is successfully used by the investigator for the measurement of power components (Fig. 5). For measurement of power, current and potential transformers are used to get the voltage and current values (Fig. 6). These two data are given to the software using NI ELVIS and DAQ card. Then the software starts giving active power, apparent power, reactive power and power factor. 


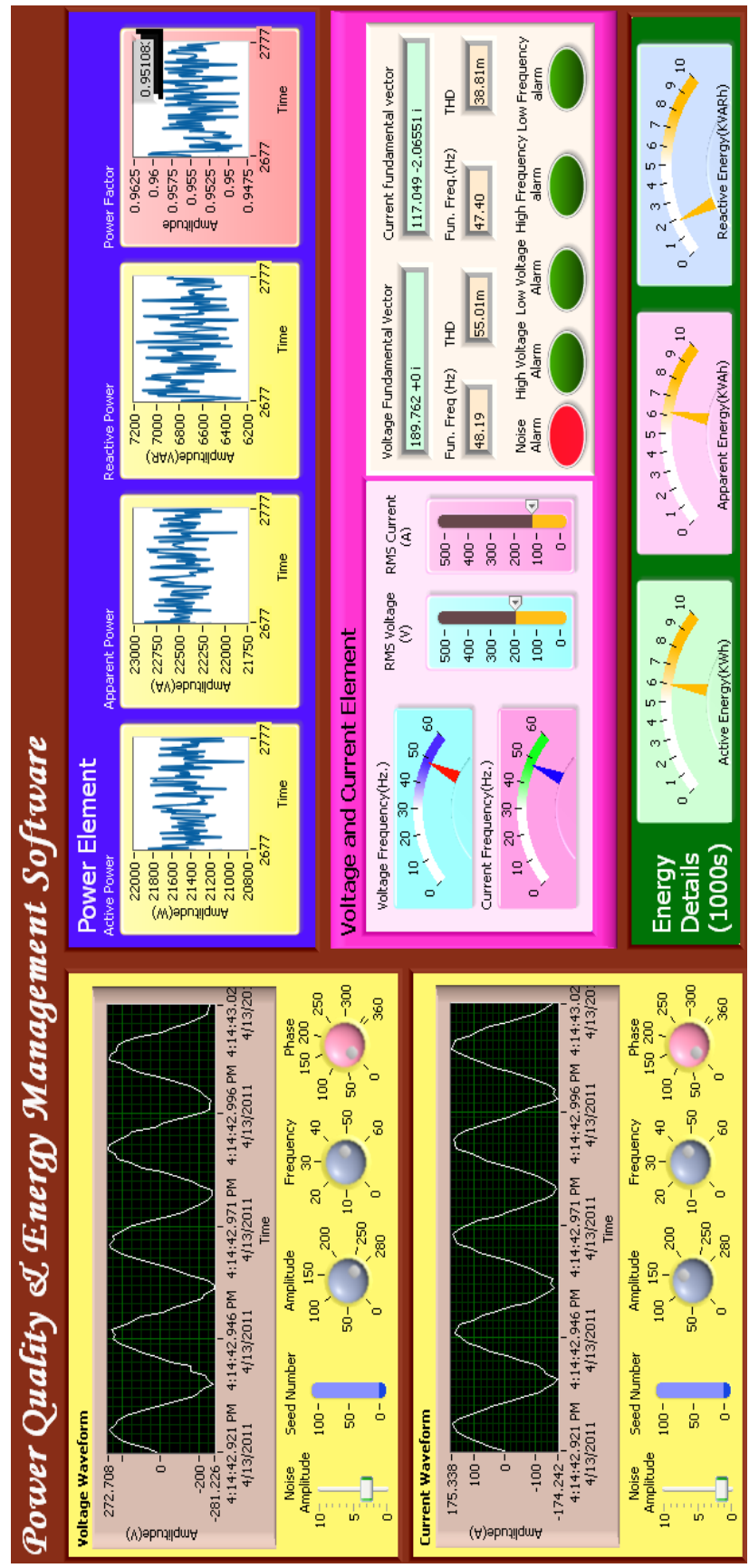

Fig. 5 - Power and energy component measurement

Power factor is one of the most important parameters in view of power quality and energy management. This software directly gives very accurate value of power factor up to seven decimal points.

\section{Case - 4: Energy component measurement}

For measurement of energy, the same hardware and software interfacing is done as explained in case -3 . Then it starts giving real time active, apparent and reactive energy values.
Case - 5: Energy management using this software

This software works as an ultimate tool for energy managers for doing energy management practice. The important electrical parameters which are used by energy managers like power factor, current and voltage fluctuations, power and energy values etc. can be easily obtained using this software (Fig. 6). Therefore by using this software energy managers can speed up their work and can work more efficiently.

\section{HARDWARE AND SOFTWARE INTERFACING}

NI ELVIS and NI DAQ card is used by the investigator. But any compatible DAQ card can be used with this software. The NI ELVIS receives real time voltage and current data from voltage transformer and current transformer respectively. Then by using DAQ card this data is given to the software input (Fig. 6). Then it starts giving real time voltage component, current component, power and energy component [9].

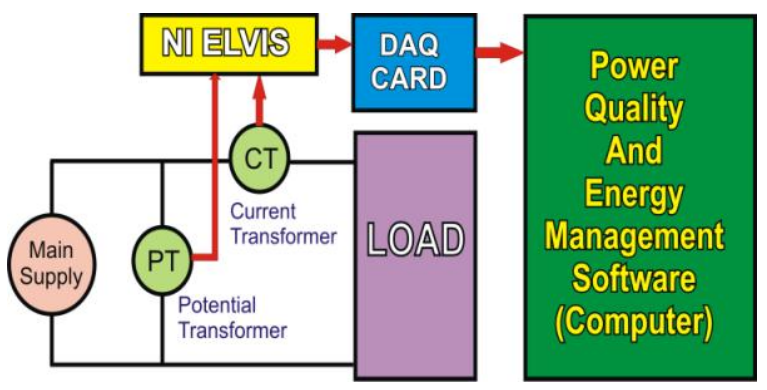

Fig. 6 - Hardware and software interfacing

\section{CONCLUSION}

The introduction of this software is a revolutionary step in the field of power quality, energy management system and green engineering. Some major points which are very useful regarding this energy management software are -

1. It gives highly accurate result with ultra high speed. So it can be an excellent choice as a power quality meter.

2. It nearly saves $75-80 \%$ of time of energy managers which increase the speed to complete work.

3. It can save million rupees instrument expenditure which is used by energy managers to monitor the power quality components like harmonic analyzers, distortion measuring instruments, energy meters etc.

4. It can be converted into standalone exe or in the form of installer also.

5. It can be also used as online monitoring and measuring tool.

6. Now a days, power failure is a common problem due to energy crisis. The best available solution is inverter. It can be used as a standard tool in inverter industries to check the power quality. 
IOSR Journal of Engineering

May. 2012, Vol. 2(5) pp: 1102-1106

7. This software is highly beneficial from power quality measurement point of view.

\section{REFERENCES}

[1] W. M. Gready and S. Santosa, "Understanding power system harmonics", IEEE power eng. rev., Vol. 21, No. 11, pp8-11, Nov, 2001

[2] Salvatore Caldara, Salvatore Nuccio, Ciro Sparta, "A virtual instrument for measurement of flicker", IEEE transaction on instrumentation and measurement, Vol. 47, October 1998

[3] A. Prudenzi, M. Di Lillo, A. Silvestri, M.C.Falvo "Software Tool for Energy Audit Activities in Building”, IEEE International Symposium on Power Electronics, Electrical Drives, Automation and Motion, August 6, 2008.

[4] Azimah Omar, Norman, Marium, Mohd Amran Mohd Radzi, "Software development for energy auditing practice", IEEE, SCORED 2003 Proceedings, Putrajaya, Malaysia, March 4, 2003.
[5] Juan Jose, Antonio, "A web-based distributed measurement system for electrical power quality monitoring”, IEEE Journal, 2009.

[6] http://www.ni.com

[7] Johnson, Gray W., "LabVIEW Power Programming", McGraw-Hill Professional Publication, 1998

[8] Riccardo de Asmundis, "LabVIEW- Modeling, Programming and Simulations", InTech Publication, 2011

[9] NI Instruments, "NI ELVIS hardware user manual" NI Instruments, August 2008 